\title{
Glauben, Handeln, Verstehen
}

\author{
Studien zur Auslegung des Neuen Testaments. Band II
}

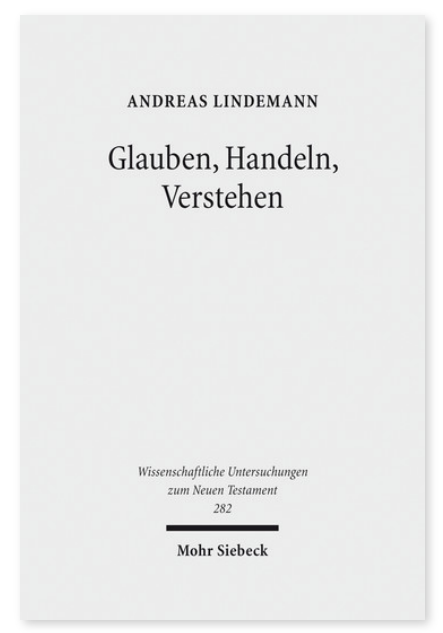

2011. X, 500 Seiten. WUNT I 282

ISBN 978-3-16-151860-7

DOI 10.1628/978-3-16-151860-7

eBook PDF $159,00 €$

ISBN 978-3-16-151683-2

Leinen $159,00 €$
In den in diesem Band enthaltenen vierzehn Studien fragt Andreas Lindemann nach dem Verhältnis des Urchristentums zu Israel und erörtert einige konkrete Aspekte neutestamentlicher und frühchristlicher Ethik; es folgen Beobachtungen zur Auslegungs- und Theologiegeschichte von der Alten Kirche über die Reformationszeit bis zur Gegenwart.

Zunächst untersucht Andreas Lindemann das komplizierte Verhältnis des entstehenden Christentums zu Israel vor allem im Blick auf die Stellung Jesu und am Beispiel der Rolle des Paulus sowie unter der Frage, welches Israel-Verständnis sich in den neutestamentlichen Schriften zeigt. Anschließend geht er Fragen der ethischen Praxis im Urchristentum nach, denen unverändert aktuelle Bedeutung zukommt - das Thema 'Gewalt', das Problem der kirchlichen Lebenswirklichkeit in einer nichtchristlichen Welt, die Praxis urchristlicher Diakonie am Beispiel der Jerusalem-Kollekte und das ethische Problem des Wertes des werdenden Lebens am Beispiel des Schwangerschaftsabbruchs. Der Bogen der weiteren Beiträge spannt sich dann von der neutestamentlichen Traditionsgeschichte der Erzählung vom »Reichen Jüngling « und ihrer Auslegung durch Klemens von Alexandria über die exegetische Arbeit des Genfer Reformators Johannes Calvin bis zu Aspekten der Geschichte der neutestamentlichen Wissenschaft im 19. und 20. Jahrhundert, mit dem konkreten Beispiel der kirchlichen und wissenschaftlichen Arbeit Hans von Sodens und Rudolf Bultmanns in den Jahren 1933 bis 1945.

Die Mehrzahl der Studien verdankt sich Anstößen und Anfragen, die unmittelbar aus dem Raum der Kirche kamen und auf die mit einem wissenschaftlich verantworteten exegetisch-theologischen Beitrag reagiert werden sollte. Für die vorliegende Veröffentlichung wurden alle Studien grundlegend bearbeitet und aktualisiert.

Andreas Lindemann Geboren 1943 in Leer (Ostfriesland); Studium der Ev. Theologie in Tübingen und Göttingen; 1975 Promotion; 1977 Habilitation; 1978-2009 Professor für Neues Testament an der Kirchlichen Hochschule Bethel; seit 2009 im Ruhestand; seit 2008 korrespondierendes Mitglied der Akademie der Wissenschaften zu Göttingen.

Jetzt bestellen:

https://mohrsiebeck.com/buch/glauben-handeln-verstehen-9783161518607?no_cache=1

order@mohrsiebeck.com

Telefon: $+49(0) 7071-923-17$

Telefax: +49 (0)7071-51104 